Check for updates

Cite this: RSC Adv., 2017, 7, 36421

Received 19th May 2017

Accepted 5th July 2017

DOI: 10.1039/c7ra05651f

rsc.li/rsc-advances

\section{Fluorescent probes and materials for detecting formaldehyde: from laboratory to indoor for environmental and health monitoring}

\author{
Anyao $\mathrm{Bi}^{\text {ab }}$ Shuqi Yang, ${ }^{\text {ab }}$ Min Liu, ${ }^{c}$ Xiaobo Wang, ${ }^{\text {ab }}$ Weihua Liao ${ }^{b}$ \\ and Wenbin Zeng (iD) *ab
}

Formaldehyde (FA), as a vital industrial chemical, is widely used in building materials and numerous living products. It has become one of the most important air pollutants in residential and industrial occupational environments. Studies have shown that FA easily reacts with nucleophilic materials, leading to the formation of DNA damage. Additionally, Alzheimer's disease is related to the intake of FA. The concentration of FA in our surroundings especially in the urban environment has attracted increasing attention. Thus, development of a rapid, sensitive and facile method to determine the concentration of FA becomes highly desirable. To date, many types of FA sensing methods have been applied to detect and quantify FA concentration. Herein, we summarized the recent development of materials for FA detection and their application in environmental and health monitoring, with a focus on fluorescent probe, nanomaterials, and biomolecules. Moreover, the future trend of related development from lab to indoors was also proposed.

\section{Introduction}

Formaldehyde (FA) has attracted significant attention in the domain of science. As a carcinogenic amphibolic toxic aldehyde, ${ }^{1}$ FA easily causes DNA damage by reacting with nucleophilic material actively. ${ }^{2}$ Small doses of FA can cause pain, emesia, somnolence and stupor, and its large amounts can cause death. ${ }^{3}$ Moreover, the Alzheimer's disease is related to the intake of FA. ${ }^{4}$ According to explicit evidence of FA detriment, the International Agency for Research on Cancer (IARC) has categorized FA in Group I, carcinogenic to humans, in $2004,^{5}$ whereas China has ranked it second in the control list of chemicals toxic to humans. ${ }^{6}$ The United States Environmental Protection Agency suggested the limit of FA as $0.2 \mathrm{mg} \mathrm{kg}^{-1}$ of body weight in daily life and WHO set it as $0.15 \mathrm{mg} \mathrm{kg}^{-1}$ There are mainly two causes that result in the high levels of FA, one is artificial additives and the other is products that themselves produce FA during their frozen storage or processing.

To make sure that FA is not pernicious to human health, it is pivotal to control FA levels via early detection. There are various types of FA detection approaches nowadays, including

aXiangya School of Pharmaceutical Sciences, Central South University, Changsha 410013, China. Fax: +86-731-82650459; Tel: +86-731-82650459. E-mail: wbzeng@ hotmail.com

${ }^{b}$ Molecular Imaging Research Center, Central South University, Changsha, 410013, China

'Department of Pharmacy, Xiangya Hospital, Central South University, Changsha 410008, China piezoelectric sensors, ${ }^{7}$ electro-chemical biosensors, ${ }^{8}$ quartz crystal microbalance, ${ }^{9,10}$ Raman spectroscopy, ${ }^{11}$ gas chromatography, ${ }^{12,13}$ liquid chromatography, ${ }^{14,15}$ X-ray diffraction (XRD), transmission electro-microscopy (TEM) ${ }^{16}$ and biosensor methods. ${ }^{17-19}$ Each detection method has different deficiency, and obvious sensor technologies are greatly needed to enable detection of FA in situ and real-time in a concise and precise manner. ${ }^{20,21}$ Compared to semiconductor sensors based on gassensitive films, ${ }^{22-25}$ fluorescent sensors relying on molecular imaging have advantages of simplicity, high sensitivity, ${ }^{26}$ and quick response. $^{27}$

Of note, the detection and quantization of FA in cell and tissue has become a new challenge and requires a new technique that is real-time and non-invasive and enables in situ detection. Molecular imaging relies on target-specific probes to achieve non-invasive detection and quantization of biomolecules in vitro and in vivo ${ }^{28-32}$ and is widely applied for accurate detection of disease and its location, and stage by collecting information on molecular pathways in cellular and biological processes underlying the diseased tissue. ${ }^{28-33}$ Obviously, molecular imaging can be clinically applied in the discovery and development of medicine, to evaluate the efficacy of drug therapy through real-time assessment ${ }^{34,35}$ and to greatly improve image-guided surgery. ${ }^{36-39}$ In recent years, the development of fluorescent probes for metal ions, anions and biomolecules has made great progress. Meanwhile, nanomaterials have attracted considerable attention, their unique structures have unique effects: for example, under light irradiation with an appropriate wavelength, the surface plasmon in 
nanomaterials is excited, so the intensity of local electric field is enormously enhanced. The application of nanomaterials has been studied in detail in various fields, especially in chemical sensing and biomedical imaging, including in the detection of FA gas. Correspondingly, the related nanomaterials used for FA detection have been documented in basic and applied sciences. Thus, we summarized different shapes of nanomaterials, including nanoparticles, nanotubes, nanosheets, and coreshell structures, for their application in FA detection.

\section{Reactivity-based small molecular fluorescent probe}

Since the synthesis of reactivity-based probe is often considered to be convenient, the fluorescence detection is advisable for determining concentration levels of FA rapidly and accurately. Hence, it has become one of the most important sensing technologies for FA detection. As mentioned above, fluorescent imaging is one of the methods of choice to visualize intracellular species in various solutions, cells and tissues due to implicit advantages of fluorescent detection methods. As such, a variety of small-molecule FA-selective fluorescent sensors have been reported in recent years. In this part, the fluorescence probes are summarized based on type and how the small molecular fluorescent probe reacts with FA.

\subsection{Schiff reactivity-based small molecular fluorescent probe}

Schiff bases are compounds with a general formula ' $\mathrm{RCH}=\mathrm{NR}$ ' that are obtained by simple condensation between equivalent amounts of aldehyde and amine with high yields. They are known to be a type of ligands with strong coordination ability. In organic synthesis, Schiff base reactions are often applied for generating carbon-nitrogen bonds. ${ }^{40}$ As mentioned above, Schiff bases have been considered to be one of the most convenient and attractive ligands for quantification of metal ions $^{\mathbf{4 1 - 4 3}}$ or organic molecular. Hence, it is an outstanding reaction for the FA fluorescent probe design. ${ }^{\mathbf{4 4 , 4 5}}$

Before 2012, only were a few fluorescent sensors were reported. ${ }^{\mathbf{4 6 , 4 7}}$ In order to develop more sensors, many research on the application of reactive fluorescent dyes that invertible binding of FA has been applied for the development of FA sensors, their characteristic fluorescence peak shifts under the presence of FA for optical detection. BODIPY is known as a useful fluorophore for its high quantum yield (UF > 0.50) and obvious and strong excitation and emission peaks. The fluorescent of BODIPY fluorophore can be quenched by introducing amine moieties through photoinduced electron transfer (PET), which further form imine functional groups with FA and restore

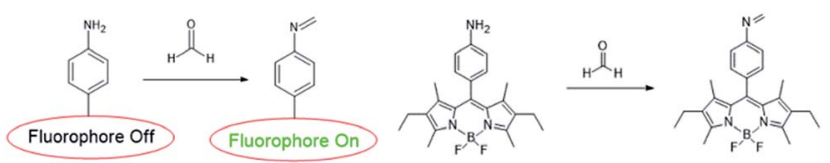

Fig. 1 FA sensing mechanism of AnB.

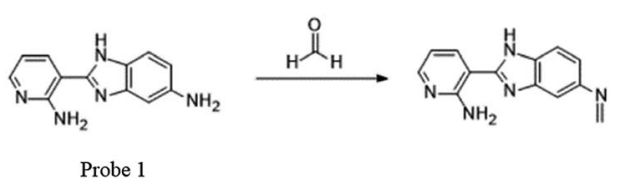

Fig. 2 FA sensing mechanism of probe 1.

its fluorescence. Sung prepared primary, secondary, tertiary, and aniline moieties (AB1, AB2, AB3, and AnB, respectively) and examined their maximum quenching BODIPY fluorescence. ${ }^{48}$ The results showed that the AnB was a stable and highly sensitive sensor system. ${ }^{49}$ In addition, it could detect FA with significantly enhanced fluorescence intensity in methanol.

To investigate fluorescence changes of AnB upon addition of FA, fluorescence titrations were carried out with $37 \%$ FA in degassed dry methanol at $\mathrm{pH}$ 8. The result is shown in Fig. 1; as the concentration of FA increases, a gradual increase in fluorescence emission intensity of $\mathrm{AnB}$ is observed due to the blocking of PET. Electron transfer (ET) quenched the fluorophore excited state from the aniline moiety to sensor-FA interactions.

Recently, many FA fluorescent probes have been developed. $\mathrm{Li}^{50}$ and his team successfully applied a fluorescent dye with strong dual-emission fluorescence in the detection of FA by introducing an amino group in the benzene ring, such as 2amidyl-3-(3-amidyl-1 $H$-benzo[ $d]$ imidazolyl)-pyridine. On the basis of this, they synthesized a sensitive and stable dualemission property fluorescent dye $\mathbf{1}$ from nicotinamide by

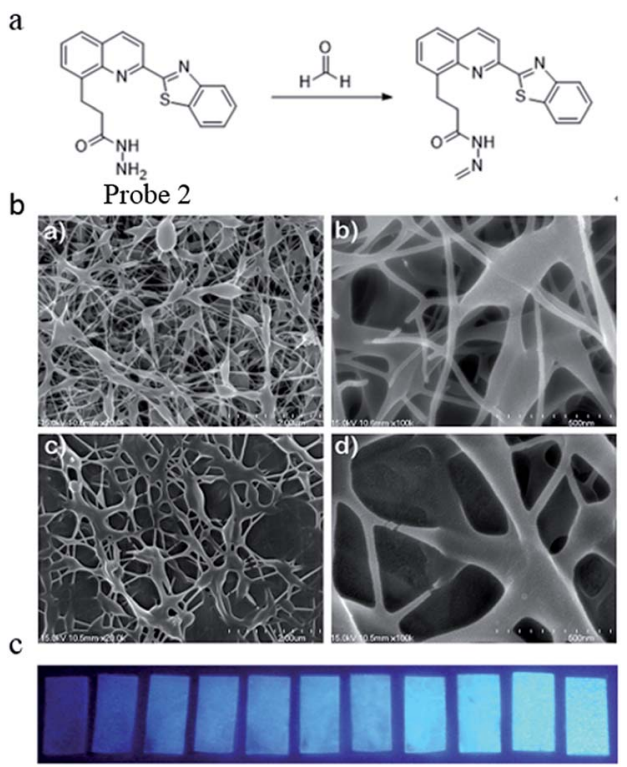

Fig. 3 (a) FA sensing mechanism of probe; (b) SEM images of polyvinyl alcohol blending probe 2 electrospun nanofibers. (a) PVA $(2 \mu \mathrm{m}),(\mathrm{b})$ PVA (500 nm), (c) 1 and PVA ( $2 \mu \mathrm{m})$, and (d) 1 and PVA (500 nm) and (c) photographs of probe $1\left(2.96 \times 10^{-2} \mathrm{wt} \%\right)$ as electrospinning test strip for the detection of formaldehyde at various concentrations (from left to right: $0 \mathrm{M}, 0.01 \mathrm{M}, 0.05 \mathrm{M}, 0.1 \mathrm{M}, 0.2 \mathrm{M}, 0.7 \mathrm{M}, 1 \mathrm{M}, 2 \mathrm{M}, 3 \mathrm{M}, 5 \mathrm{M}, 7 \mathrm{M}$, $10 \mathrm{M}$ ) in water (this figure has been reproduced from ref. 51 with permission from Elsevier). 
a three-step procedure in a yield of $86.7 \%$. Upon excitation at $365 \mathrm{~nm}$, the concentration of FA increased and a gradual increase in fluorescence emission intensity was observed due to the blocking of PET (Fig. 2). Before sensor-FA interactions, the fluorophore excited state exhibited no fluorescence due to electron transfer (ET) between aniline moiety and pyridine fluorophore. The frontier orbital diagram indicated that HOMO energy of imine $(-5.382 \mathrm{eV})$ was lower than that of $\mathbf{1}(-5.014 \mathrm{eV})$ after the interactions, thus prohibiting PET quenching of the emission. Later research showed that the fluorescence peak at about $515 \mathrm{~nm}$ disappeared and a red-shift from $409 \mathrm{~nm}$ to $415 \mathrm{~nm}$ was observed on introduction of FA, indicating the relationship between FA concentration and fluorescence intensity at $415 \mathrm{~nm}$. Also, the lower limit of detection (LOD) from the fluorescence titration experiment was calculated to be as low as $10 \mu \mathrm{M}$. The fluorescence spectra of 1 with time showed that $\mathrm{HCHO}$ could be detected within $48 \mathrm{~s}$ when its concentration was more than $6.67 \times 10^{-2} \mathrm{M}$.

In the same year, $\mathrm{Yu}^{51}$ reported a stable and highly sensitive fluorescent probe based on 8-hydroxyquinoline. Probe 2 was synthesized via a four-step procedure beginning from 2-methyl8 -hydroxyquinoline with a yield of $68.8 \%$. The DMSO solution of the probe was then slowly added to a mixture of deionized water and $3 \mathrm{~g}$ polyvinyl alcohol and stirred for $2 \mathrm{~h}$ at $80{ }^{\circ} \mathrm{C}$. After cooling to room temperature and stirring for $30 \mathrm{~min}$, the resulting clear homogenous solution with $10 \%$ polyvinyl alcohol was used for electrospinning the film. Through highvoltage spinning, a solid-state FA probe with electrospinning fibers containing fluorescent compounds was developed and the SEM images are shown in Fig. 3a. Upon the addition of FA, a significant turn-on fluorescence response (5.5-fold fluorescence enhancement) with a maximum at $467 \mathrm{~nm}$ was observed due to the blocking of PET. The fluorescence properties were studied by a UV lamp and the results in Fig. 3 b show that clear fluorescence enhancement was observed as the concentration of FA increased.
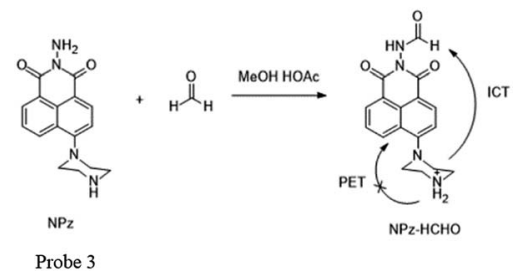

Fig. 4 FA sensing mechanism of NPz (probe 3).
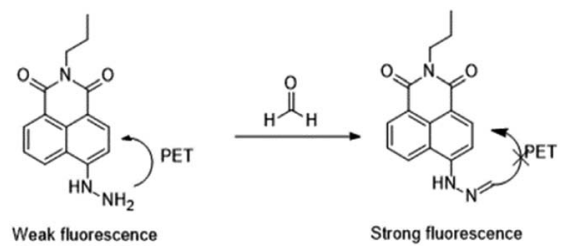

Probe 4
Fig. 5 FA sensing mechanism of $\mathrm{Na}-\mathrm{FA}$ (probe 4).
Meanwhile, Lin and his team ${ }^{52}$ have made considerable effort in FA detection. They found that the acylation reaction of hydrazine can be applied for synthesizing fluorimetric derivatization reagents for FA detection. For example, they synthesized 1,8-naphthalimides named NPz (probe 3) with a yield of $36 \%$ and examined its fluorescence behavior toward FA in MeCN containing 5\% HOAc (Fig. 4). During the addition of FA, the fluorescence intensity was found to be linearly proportional $(R=0.9970)$ to FA in the concentration range of $0-1.6 \mathrm{mM}$. In addition, the low detection limit of $0.25 \mathrm{ppm}(\mathrm{S} / \mathrm{N}=3)$ indicated that NPz was sensitive and potentially useful for FA detection in the environment.

Later, $\operatorname{Lin}^{53}$ reported a two-photon fluorescent probe based on 1,8-naphthalimides. Probe 4 could detect endogenous FA for the first time in living tissues due to the two-photon technology, ${ }^{54}$ which offers much deeper penetration of biological samples. Similar to previous 1,8-naphthalimide derivatives, the synthesis of this probe was straightforward. When FA was added dropwise, a notable consuming fluorescence peak at $543 \mathrm{~nm}$ was observed. Significantly, after treating with $100 \mathrm{~mm}$ of FA for $30 \mathrm{~min}$, the 5 $\mathrm{mm}$ probe had a 900 -fold increase in fluorescence. The probe was further applied to monitor endogenous FA in living cells. The HeLa cells incubated with $\mathrm{NaHSO}_{3}$ inhibitor displayed no emission (Fig. 6b), while in the two-photon mode, cells treated with probe Na-FA exhibited green fluorescence (Fig. 6e). Meanwhile, nearly no emission was observed when cells were incubated with the probe after pre-treatment with the inhibitor (Fig. 6h). These results demonstrated that the probe can detect endogenous FA in living cells (Fig. 5).

Kim and Lin $^{55}$ cooperatively developed a naphthalimide-based FA probe 5 employed a biotin pendant as a cancer targeting moiety. The spectroscopic properties of the probe in the absence and presence of FA were first assessed. Upon the addition of FA, the fluorescence response had a linear relationship between the

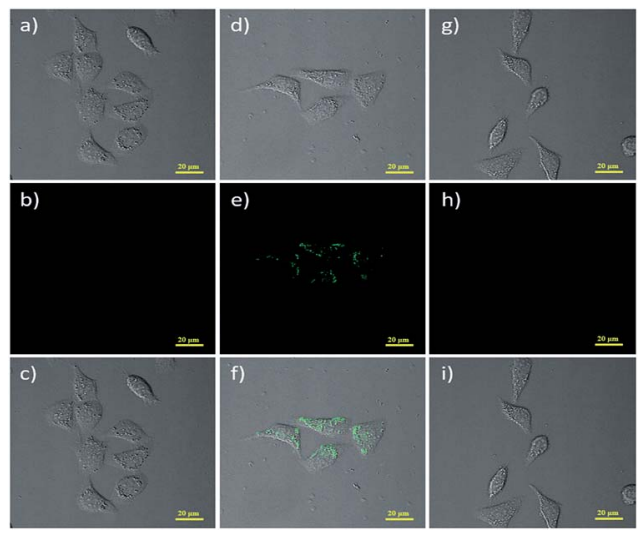

Fig. 6 Two-photon fluorescence imaging of endogenous FA in living HeLa cells. Bright-field images of HeLa cells treated with (a) $\mathrm{NaHSO}_{3}$ $(200 \mathrm{~mm}),(\mathrm{d}) \mathrm{Na}-\mathrm{FA}(5 \mathrm{~mm})$, and $(\mathrm{g})$ incubated with $\mathrm{NaHSO}_{3}(200 \mathrm{~mm})$ and then with the probe Na-FA (probe 4) $(5 \mathrm{~mm})$; two-photon fluorescence image of HeLa cells treated with (b) $\mathrm{NaHSO}_{3}(200 \mathrm{~mm})$, (e) probe $4(5 \mathrm{~mm})$ and $(\mathrm{h})$ incubated with $\mathrm{NaHSO}_{3}(200 \mathrm{~mm})$ and then with probe 4 ( $5 \mathrm{~mm})$; and (c), (f) and (i) represent the merged image of (a), (b) and (d) and (e), (g) and (h), respectively (this figure has been adapted from ref. 53 with permission from Wiley). 


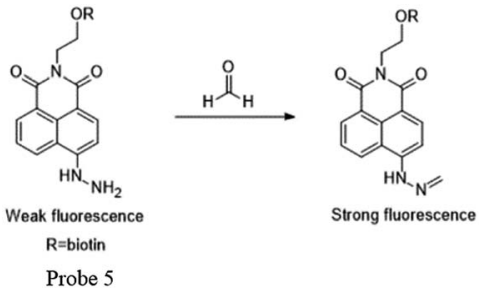

Fig. 7 FA sensing mechanism of probe 5-biotin.
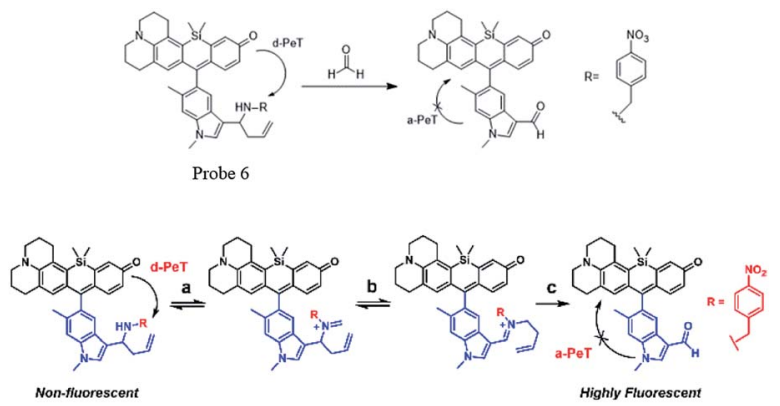

Fig. 8 FA sensing mechanism of probe 6 (this figure has been adapted from ref. 60 with permission from ACS).

fluorescence intensity and FA concentration up to $10 \mathrm{mM}$, with the LOD as $0.78 \mathrm{mM}$. Subsequently, the probe was applied to fluorescent imaging experiments in living cells. Herein, probe $\mathbf{5}$ showed a relatively brighter fluorescence in the biotin receptor positive cell line compared to that in the negative cell line, indicating that the probe is a promising candidate for endogenous FA detection in cancer cells and tissues, with a high selectivity and low detection limit (Fig. 7 and 8).

\subsection{Aza-Cope reactivity-based small molecular fluorescent probe}

Chemical reactions such as ring-opening reaction, ${ }^{56}$ hydrozone formation, ${ }^{57}$ cyclization $^{58}$ and nucleophilic addition ${ }^{59}$ have been developed to detect FA. These chemical reaction-based probes provide aggressive approaches for FA detection. Aza-Cope rearrangement has recently been applied to develop new fluorescent probes. For example, Chan et al. ${ }^{60}$ developed FP-1 probe to visualize FA in living HEK293TN and neuroscreen-1 cells. Also, FAP-1 has been reported by Chang et al. ${ }^{61}$ which is based on 2-aza-Cope rearrangement reaction and has been employed in living cells for imaging FA.

Chan et al. ${ }^{60}$ reported a new approach for FA detection in living cells through the development of FA probe 6 (FP1), a FAresponsive fluorescent indicator. The probe comprised three parts: a fluorescent core, an FA reactive moiety, and a dark quencher. FP1 was synthesized starting from the reaction between tert-butyllithium and indole 2, which could yield a lithium adduct and subsequently react with silicon xanthone 1. Silicon rhodol 3 was yielded after sequential acid-mediated dehydration and $\mathrm{BBr} 3$ demethylation reactions. The indole moiety was subjected to Vilsmeier-Haack formylation
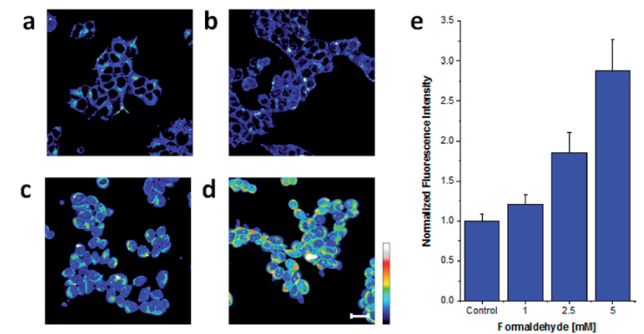

Fig. 9 Confocal microscopy images acquired by irradiation of HEK293TN cells treated with (a) a DMEM vehicle control, (b) 1, (c) 2.5, and (d) $5 \mathrm{mM} \mathrm{FA}$ for $3 \mathrm{~h}$ at $37^{\circ} \mathrm{C}$ with a $633 \mathrm{~nm}$ HeNe laser. Scale bar represents $20 \mu \mathrm{m}$. Pseudo-coloring represents intensity distribution from highest intensity indicated by white to lowest intensity designated by black. (e) Quantification of imaging data (this figure has been adapted from ref. 60 with permission from ACS).

conditions to furnish carboxaldehyde 4 , which was transformed to homoallylic amine 5 with potassium allyltrifluoroborate in methanolic ammonia. Finally, reductive amination was carried out with 4-nitrobenzaldehyde and triacetoxyborohydride. Upon the addition of FA, the fluorescence was increased in a dosedependent manner. Inspired by the excellent selectivity and exceptional responsiveness to FA in vitro, FP1 was employed to visualize FA in living cells. Incubated with $2 \mu \mathrm{M}$ FP1 at $37^{\circ} \mathrm{C}$ for 8 min, HEK293TN cells were subsequently treated with a buffer containing FA at $0,1,2.5$, or $5 \mathrm{mM}$ for $3 \mathrm{~h}$. As shown in Fig. 9, a 3 -fold fluorescence enhancement was observed upon the addition of 5 mM FA.

Chang and his team ${ }^{61}$ reported that FA-induced 2-aza-Cope reaction could transform a homoallylic amine into an aldehyde and thus induce a fluorogenic turn-on response. Thus, the authors prepared a FA probe FAP-1 (probe 7), utilizing a key boronate-mediated aminoallylation as the reactive trigger. Upon reaction with FA, an aldehyde product would be yielded, which is incapable of spirocyclization and would produce fluorescence. The probe was reported to exhibit an 8-fold fluorescence enhancement upon treatment with $100 \mu \mathrm{M}$ FA in pH 7.4 aqueous buffer solution. Then, the ability of FAP- 1 to visualize FA in living cells was tested with HEK293T cells. The cells were incubated with $10 \mu \mathrm{M}$ probe 7 for $30 \mathrm{~min}$ and various concentrations of FA (from $200 \mu \mathrm{M}$ to $1 \mathrm{mM}$ ) were added. A notable and dose-dependent turn-on fluorescence could be observed in the FA-treated cells over control cells,
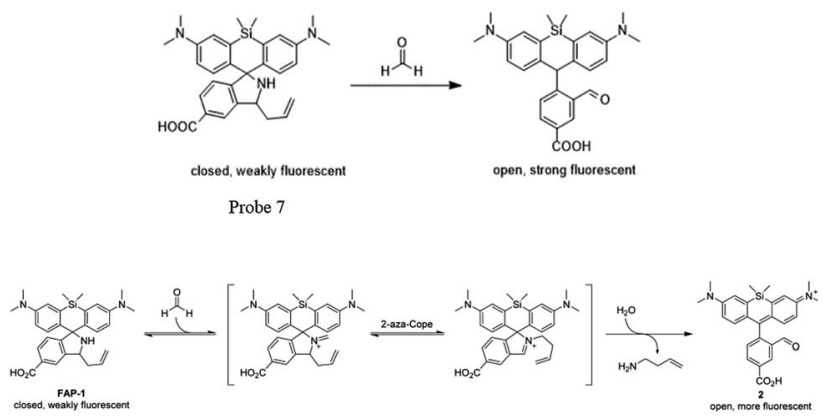

Fig. 10 FA sensing mechanism of probe 7 (this figure has been adapted from ref. 61 with permission from ACS). 
demonstrating probe 7 was capable of detecting FA in a cellular context (Fig. 11).

Lin et al. ${ }^{62}$ prepared a novel ratiometric fluorescent FA probe (probe 8), employing 6-hydroxy naphthalene chromophore as the fluorescent core and homoallylamino group as the trigger. Probe 8 was easily obtained in the yield of $66 \%$. Upon treatment with an increasing amount of FA (1.0 to 300.0 equiv.), the emission intensity at $451 \mathrm{~nm}$ was significantly enhanced, while the peak at $359 \mathrm{~nm}$ decreased. Then, HeLa cells were employed to evaluate the practicability of the probe. Incubated with RFFP $(10 \mathrm{mM})$ for $30 \mathrm{~min}$, the cells were then treated with different doses of FA ( 0.5 and $1 \mathrm{mM}$ ) for another 2 hours. The results showed that the probe generated a distinct increase in emission intensity (green/blue) in the ratiometric fluorescence images, demonstrating its ability of FA detection in both aqueous solutions and biological samples (Fig. 10).

\section{Nanomaterials}

Nanomaterials have attracted considerable attention from the early 1980s due to their special physical and chemical properties and promising applications. ${ }^{63}$ Owing to different shapes of nanomaterials, they can be divided into many categories: nanoparticles, nanotubes, nanosheets, core-shell structures and so on. The unique structure makes them have many unique effects: surface effect and small size effect and they can exhibit characteristics of size- and shape-dependent plasmon resonance scattering and absorption. ${ }^{64,65}$ Under irradiation with light of an appropriate wavelength, the surface plasmon in nanomaterials can be excited, so that the intensity of the local electric field is enormously enhanced. This is the basis for various spectroscopic techniques sensitive to electromagnetic fields, especially of that for surface-enhanced Raman spectroscopy (SERS). ${ }^{6-68}$ Entering the 21st century, the research on nanomaterials in various fields became more detailed, especially in chemical sensing and biomedical imaging such as the
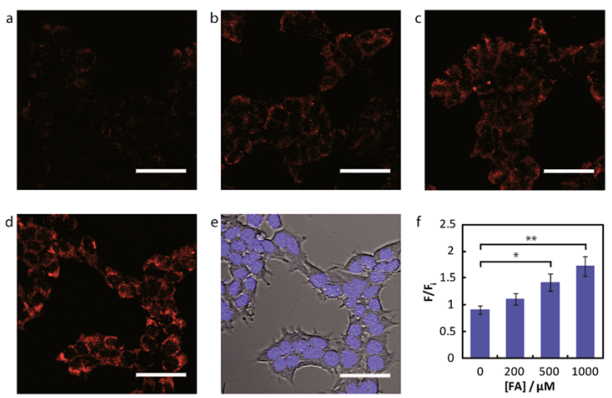

Fig. 11 Confocal microscopy of FA detection in living HEK293T cells using probe 7. Cells were treated with $10 \mu \mathrm{M}$ probe 7 in BSS for $30 \mathrm{~min}$ at $37^{\circ} \mathrm{C}$, followed by an exchange with fresh BSS and addition of varying FA concentrations. Images are taken 30 min after addition of (a) vehicle, (b) $200 \mu \mathrm{M} \mathrm{FA}$, (c) $500 \mu \mathrm{M} \mathrm{FA}$, and (d) 1 mM FA. (e) Bright-field image of cells in (d) overlaid with image of $1 \mu \mathrm{M}$ Hoechst 33342. Scale bar represents $50 \mu \mathrm{m}$ in all images. (f) Mean fluorescence intensities of HEK293T cells treated with varying concentrations of FA for 30 min relative to mean fluorescence intensity before FA addition; error bars denote SEM (this figure has been adapted from ref. 61 with permission from ACS).

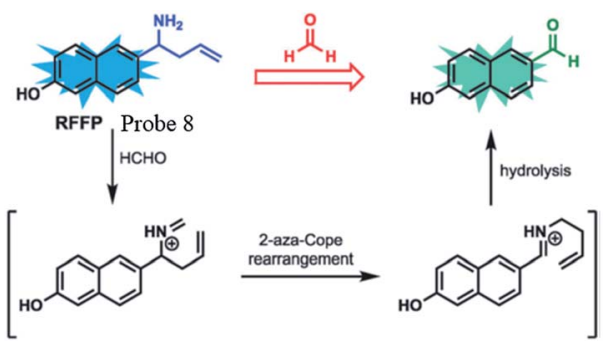

Fig. 12 FA sensing mechanism of probe 8 (this figure has been adapted from ref. 60 with permission from RSC).
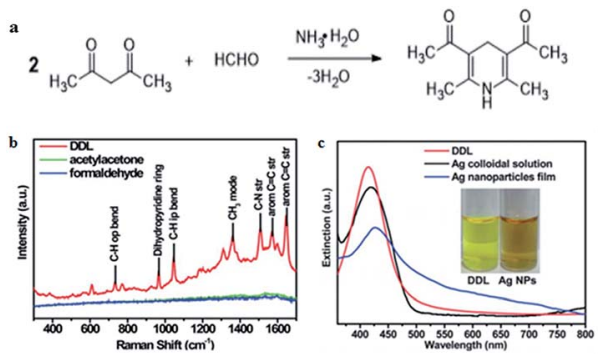

Fig. 13 (a) Hantzsch reaction between FA and acetylacetone (acac), (b) Raman spectra of $10 \mathrm{mM} \mathrm{DDL}$, acetylacetone, and FA at $457 \mathrm{~nm}$ excitation wavelength. (c) UV-vis spectra of DDL and AgNPs. The inset shows the photograph of DDL and AgNP solution under sunlight (this figure has been reproduced from ref. 69 with permission from RSC).

detection of FA gas, and some studies related to nanomaterials for FA detection were also reported (Fig. 12).

\subsection{Nanoparticles}

In recent years, SERS has attracted more and more attention owing to its superior capacity, which can enhance normally weak Raman signal to trace the analyte accurately. Some metal nanoparticles such as Ag and Au nanoparticles have been widely used as substrates of SERS because of their special enhancement effect owing to surface plasmon resonance (SPR) on the metal surface. For example, Qu and co-workers ${ }^{69}$ reported a surface enhanced resonance Raman scattering (SERRS) probe for the selective detection of FA indirectly by detecting the product of the Hantzsch reaction between FA and acetylacetone called dihydropyridine 3,5-diacetyl-1,4-dihydrolutidine (DDL, Fig. 13a). DDL exhibits a high SERS cross-section, as shown in Fig. 13b. At the same time, silver nanoparticles were employed as a substrate that exhibits a typical LSPR peak centered at $420 \mathrm{~nm}$ and partially overlaps the absorption of DDL (Fig. 13c). As a result of $\mathrm{Ag}$ nanoparticle aggregation, SERS signals were enhanced obviously. The lower limit of detection was $10^{-11} \mathrm{M}$ and the probe could be applied for the analysis of FA in practical lake-water samples, with a detection limit lower than $0.1 \mathrm{nM}$.

Ma et al. ${ }^{70}$ demonstrated the use of silver nanoparticles $(\mathrm{Ag}$ NPs) for low-powered, easy to apply real-time detection devices of FA both in environmental water and food samples. The sensing mechanism is shown in Fig. 14a, and it relies on a derivative reaction of FA with 4-amino-5-hydrazino-3- 

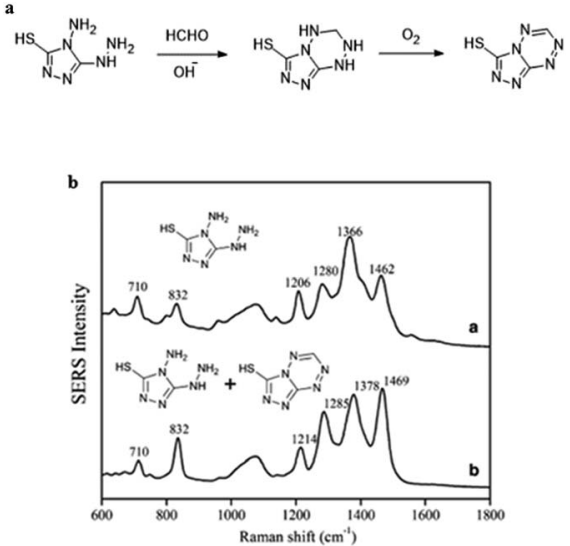

Fig. 14 (a) Derivative reaction of FA and AHMT under alkaline conditions. (b) SERS spectra of $500 \mu \mathrm{L}$ (a) AHMT in deionized water and (b) AHMT-MTT mixture in $\mathrm{HCHO}$ solution (this figure has been reproduced from ref. 70 with permission from Springer).

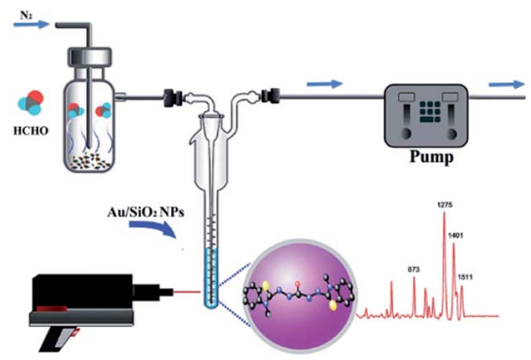

Fig. 15 Schematic of the mechanism of FA detection from aquatic products (this figure has been adapted from ref. 71 with permission from RSC).

mercapto-1,2,4-triazole (AHMT) in the nanoparticles, and 6mercapto-5-triazolo[4,3- $b]-s$-tetrazine (MTT), the product of the derivative reaction, was quantified by SERS at $832 \mathrm{~cm}^{-1}$ using $\mathrm{Ag}$ NPs as the substrate (Fig. 13b). The concentration of FA could be quantified in the $1-1000 \mu \mathrm{g} \mathrm{L}^{-1}$ range using the described method, and the limit of detection was $0.15 \mu \mathrm{g} \mathrm{L}^{-1}$. In addition, FA in food and environmental water samples were analyzed by that above method, and the obtained results had no significant difference with the actual situation, which suggests that the method is a suitable candidate to detect FA in food and water.

However, SERS substrates based on pure metals still remain a challenge in practical application due to their poor reproducibility and stability. Therefore, some nanoparticles doped with other materials were proposed by researchers. For instance, Zhang et al. ${ }^{71}$ successfully developed $\mathrm{Au} / \mathrm{SiO}_{2}$ nanoparticle-based SERS to detect FA. As shown in Fig. 15, the FA gas was separated and collected from aquatic products by negative pressure of the sampling pump, and then through a series of reactions, the product was combined with the nanoparticles and identified by SERS. In their work, the detection mechanism was based on a specific derivatization reaction between FA and MBTH (Fig. 16a), and the product of the
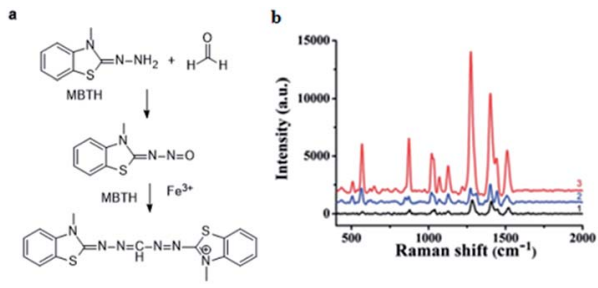

Fig. 16 (a) Derivatization reaction between FA and MBTH hydrochloride, (b) Raman spectra of MBTH with $\mathrm{Au} / \mathrm{SiO}_{2} \mathrm{NPs}$ (1), the derivative product before (2) and after (3) the addition of $\mathrm{Au} / \mathrm{SiO}_{2} \mathrm{NPs}$ at 785 excitation wavelength (this figure has been adapted from ref. 71 with permission from RSC).
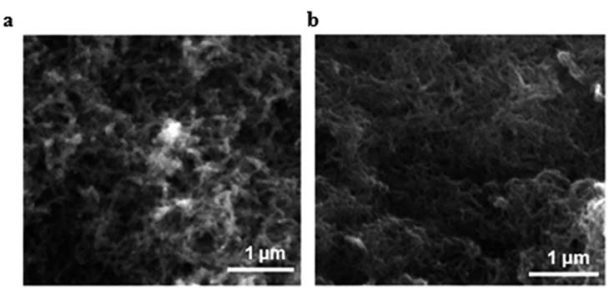

Fig. 17 SEM images of (a) polyaniline and (b) 25\% silver nanoparticles (this figure has been adapted from ref. 72 with permission from Taylor \& Francis).

derivatization reaction as a Raman-active analyte could be detected and quantified via SERS employing $\mathrm{Au} / \mathrm{SiO}_{2}$ nanoparticles (NPs) as the substrate to enhance Raman signal intensity significantly. As shown in Fig. 16b, the derivative product can generate a strong signal after addition of $\mathrm{Au} / \mathrm{SiO}_{2}$ NPs. Under optimal conditions, an extremely lower limit of detection of $0.17 \mathrm{mg} \mathrm{L}^{-1}$ is obtained, and the peak areas of the SERS are linearly related to the concentration of FA in the 0.13$0.21 \mathrm{mg} \mathrm{kg}^{-1}$ range. Additionally, this method can rapidly quantify the volatile formaldehyde in squid and shrimp samples on-site.

In some recent studies, it has been verified that polyaniline/ silver nanoparticles provide enhanced performance in applications compared with single-component sensors, and they are useful as a sensor to detect many substances like FA. For example, Zhang et al. ${ }^{72}$ used a polyaniline/silver nanoparticle as
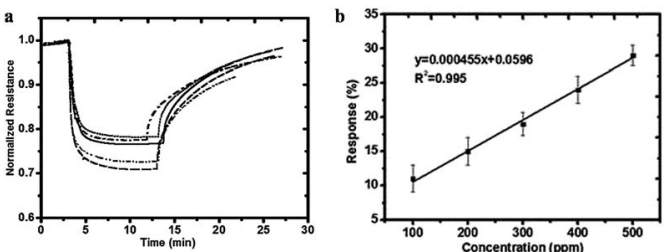

Fig. 18 (a) Responses to 500 ppm formaldehyde at room temperature for pure polyaniline (dotted line), 18\% silver nanocomposite (dashed dotted line), $25 \%$ silver nanocomposite (dashed), 31\% silver nanocomposite (solid line), and 37\% silver nanocomposite (dashed dotted line). (b) Response of the $25 \%$ silver nanocomposite sensor as a function of formaldehyde concentration at room temperature (this figure has been adapted from ref. 72 with permission from Taylor \& Francis). 


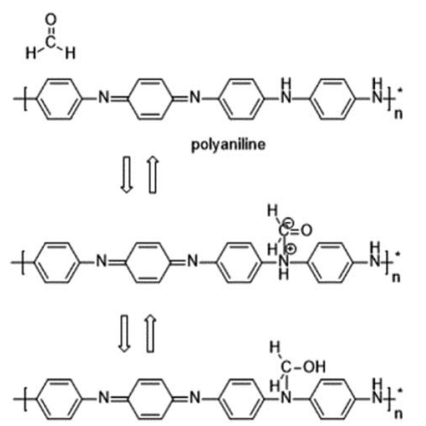

Fig. 19 Nucleophilic addition reaction between polyaniline and FA.

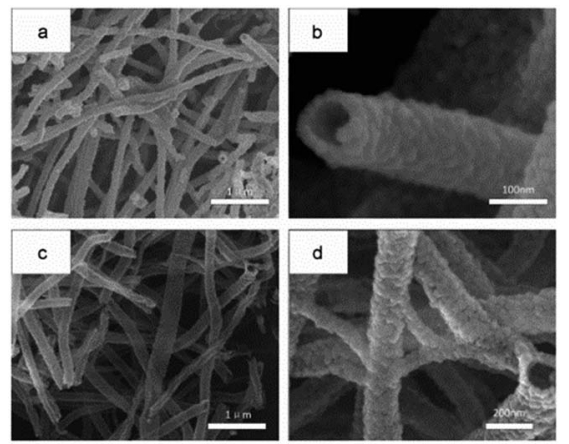

Fig. 20 (a) Low- and (b) high-magnification SEM images of $\ln _{2} \mathrm{O}_{3}$ and (c) low- and (d) high-magnification SEM images of $\mathrm{Fe}_{2} \mathrm{O}_{3}-\mathrm{In}_{2} \mathrm{O}_{3}$ nanotubes after annealing at $500{ }^{\circ} \mathrm{C}$ (this figure has been adapted from ref. 73 with permission from Elsevier).

a FA vapor sensor, and compared with the response from pure polyaniline, the response of the nanoparticles to FA was more obvious in transmission electron microscopy, scanning electron microscopy, X-ray diffraction and other scanning techniques. Scanning electron micrographs of polyaniline and the nanoparticles are shown in Fig. 17. The mechanism of the polyaniline gas sensor related to a nucleophilic addition interaction between polyaniline and FA is shown in Fig. 18; at the same time, the AgNPs can improve the mobility of the charge carriers by decreasing the distance of charge carriers in localized states, thereby resulting in an enhanced response upon exposure to FA. But when the silver concentration increased, more AgNPs aggregated in clusters, leading to a region depleted of electrons. After investigating several test data, a conclusion was generated: $25 \%$ is the best concentration of silver in nanoparticles, and the lower detect limit of FA in the 25\% AgNPs is 1.24 ppm (Fig. 19).

\subsection{Nanotubes, nanorods and nanobundles}

Pure $\mathrm{In}_{2} \mathrm{O}_{3}$ and $\mathrm{Fe}_{2} \mathrm{O}_{3}$ are all n-type semiconductors with great gas-sensing properties for FA, but both of them have obvious shortcomings such as slow response and recovery, limiting their application. Hence, researchers are trying to take some measures like mix two or more kinds of materials to change their characteristics and enhance their FA sensing properties. For instance, Zhang and co-workers ${ }^{73}$ synthesized an $\mathrm{Fe}_{2} \mathrm{O}_{3}-$ $\mathrm{In}_{2} \mathrm{O}_{3}$ nanotube as an FA gas sensor, and the change in
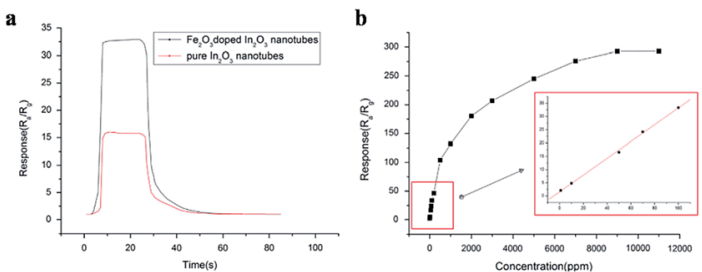

Fig. 21 (a) Response and recovery curves for $\ln _{2} \mathrm{O}_{3}$ and $\mathrm{Fe}_{2} \mathrm{O}_{3}-\mathrm{In}_{2} \mathrm{O}_{3}$ nanotube gas sensors to $100 \mathrm{ppm}$ formaldehyde (b) response of $\mathrm{Fe}_{2} \mathrm{O}_{3}-\mathrm{In}_{2} \mathrm{O}_{3}$ nanotube sensors to different formaldehyde concentrations at $250{ }^{\circ} \mathrm{C}$. The inset shows the calibration curve for 1100 ppm (this figure has been adapted from ref. 73 with permission from Elsevier).

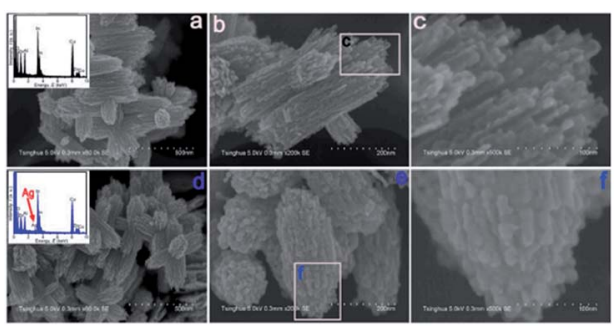

Fig. 22 (a) Low-, (b) medium-, and (c) high-magnification SEM images of $\mathrm{In}_{2} \mathrm{O}_{3} / \mathrm{ZnO}$ bundles, and (d) low-, (e) medium-, and (f) highmagnification SEM images of Ag-modified $\mathrm{In}_{2} \mathrm{O}_{3} / \mathrm{ZnO}$ bundles (this figure has been adapted from ref. 74 with permission from MDPI).

resistance induced by FA's reaction could be characterized on the nanotube surface by various detection methods. The SEM images of $\mathrm{In}_{2} \mathrm{O}_{3}$ and $\mathrm{Fe}_{2} \mathrm{O}_{3}-\mathrm{In}_{2} \mathrm{O}_{3}$ nanotubes are shown in Fig. 20. The sensing mechanism was related to the adsorption of oxygen species and electron transfer on the surface. FA molecules could react with adsorbed oxygen species on the surface and release electrons in the conduction band, resulting in resistance decrease. Compared with pure $\operatorname{In}_{2} \mathrm{O}_{3}$ nanotubes, $\mathrm{Fe}_{2} \mathrm{O}_{3}-\mathrm{In}_{2} \mathrm{O}_{3}$ nanotube sensors have a better response with FA. The response of $\mathrm{Fe}_{2} \mathrm{O}_{3}-\mathrm{In}_{2} \mathrm{O}_{3}$ nanotube gas sensors to $100 \mathrm{ppm}$ FA is almost twice that of $\operatorname{In}_{2} \mathrm{O}_{3}$ nanotubes (Fig. 21).
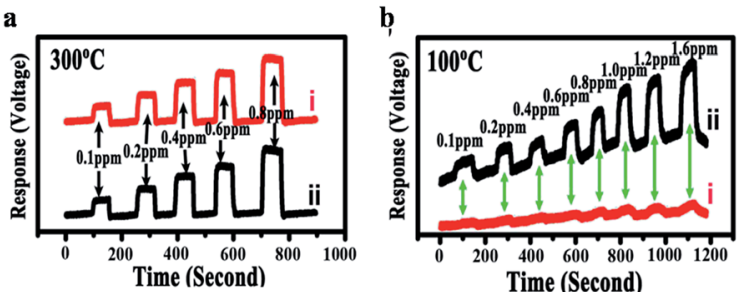

Fig. 23 (a) Response curve of a sensor coated with $\ln _{2} \mathrm{O}_{3} / \mathrm{ZnO}$ nanobundles (line i) and $\mathrm{Ag}$-modified $\mathrm{In}_{2} \mathrm{O}_{3} / \mathrm{ZnO}$ nanobundles (line ii) at $300{ }^{\circ} \mathrm{C}$ in $\mathrm{HCHO}$ with a concentration of $100-800 \mathrm{ppb}$; the $\mathrm{HCHO}$ gas was repeatedly introduced into the measurement system and then shut down; (b) response curves of a sensor coated with $\ln _{2} \mathrm{O}_{3} / \mathrm{ZnO}$ nanobundles (line i) and $\mathrm{Ag}$-modified $\mathrm{In}_{2} \mathrm{O}_{3} / \mathrm{ZnO}$ nanobundles (line ii) at $100^{\circ} \mathrm{C}$ in $\mathrm{HCHO}$ with a concentration of $100-1600 \mathrm{ppb}$ (this figure has been adapted from ref. 74 with permission from MDPI). 
Fang et al. ${ }^{74}$ designed an Ag-modified $\operatorname{~}_{2} \mathrm{O}_{3} / \mathrm{ZnO}$ bundle with micro/nanoporous structures to trace FA significantly, because the high surface area of porous structures could enhance the sensitivity of FA gas. The SEM images of $\operatorname{In}_{2} \mathrm{O}_{3} / \mathrm{ZnO}$ and Agmodified $\mathrm{In}_{2} \mathrm{O}_{3} / \mathrm{ZnO}$ nanobundles are shown in Fig. 22. From these two samples, it can be indicated that the surface morphology of the $\operatorname{In}_{2} \mathrm{O}_{3} / \mathrm{ZnO}$ nanobundles are not affected by the Ag modification process. The possible FA gas-sensing mechanism is related to the surface of that sensor to be porousstructure, which when operated by nanogaps in Ag-modified $\mathrm{In}_{2} \mathrm{O}_{3} / \mathrm{ZnO}$ nanobundles, may provide larger surface areas and more active sites than normal $\mathrm{In}_{2} \mathrm{O}_{3} / \mathrm{ZnO}$ nanobundles. The Agmodified $\mathrm{In}_{2} \mathrm{O}_{3} / \mathrm{ZnO}$ nanobundles exhibit superior response with FA gas: the response and recovery times are as short as $6 \mathrm{~s}$ and $3 \mathrm{~s}$, respectively, and the lower limit of FA detection was approximately $100 \mathrm{ppb}$, which fits with the health standard limitation on FA concentration in air. Hence, this method is suitable for industrial and practical applications (Fig. 23).

Besides to SRES, nanomaterials can be applied as substrates in many other approaches such as Rayleigh scattering (RRS) and density functional theory (DFT) due to their individual electronic properties. In 2014, Wen et al. ${ }^{75}$ developed a new gold nanorod (AuNRs) surface plasmon resonance Rayleigh scattering-energy transfer (RRS-ET) method to trace FA with rapidly and with good selectivity and repeatability. The SEM images of AuNRs are shown in Fig. 24. In that research, in a $\mathrm{KOH}$ medium, the AuNRs were aggregated to for large AuNR aggregates, which exhibited strong RRS signal at $440 \mathrm{~nm}$, and then FA reacted with 4-amino-3-hydrazino-5-mercap-1,2,4triazole (AHMT) under the AuNR substrate to form a purplish red compound, 6-mercapto- $S$-triazole [4,3- $b]-S$-tetrazole (MTT). As the receptor, the MTTs had hydrophobicity close to that of the AuNR aggregates as the donor; when the system was irradiated by $440 \mathrm{~nm}$ photons, the RRS signal was triggered by RRS$\mathrm{ET}$, so that the peak at $440 \mathrm{~nm}$ was quenched (Fig. 25). The concentration of FA could be quantified in the $0.25-48 \mu \mathrm{mol} \mathrm{L}^{-1}$ range using the described method. In addition, after experimental verification, the described method could be applied to the analysis of FA in indoor and polluted air samples with high selectivity and repeatability.

In the other explorations, Yoosefiana et $a l^{76}$ reported $\mathrm{Pd}-$ loaded on the surface of a single-walled carbon nanotube $(\mathrm{Pd} /$ SWCNT) based on the density functional theory (DFT) for selective detection of FA; compared with a pristine single-walled

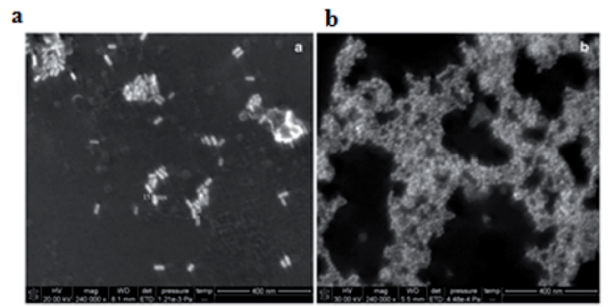

Fig. 24 SEM images of (a) $\mathrm{KOH}-\mathrm{AHMT}-\mathrm{AuNR}$ systems and (b) $\mathrm{KOH}-$ AHMT-AuNPs systems (this figure has been adapted from ref. 75 with permission from Springer).

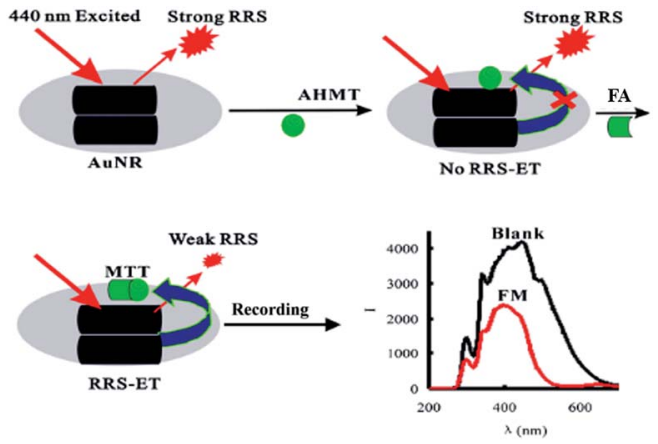

Fig. 25 Schematic of RRS-ET method for detection of FA (this figure has been adapted from ref. 75 with permission from Springer).

carbon nanotube, $\mathrm{Pd} / \mathrm{SWCNT}$ exhibited a superior response because of its better electronic properties. The variation in electronic properties of $\mathrm{Pd} / \mathrm{SWCNT}$ before and after adsorption of the detected FA. After reaction with Pd/SWCNT, the $\mathrm{O}$ atom of FA would prefer to close $\mathrm{Pd} / \mathrm{SWCNT}$ rather than the $\mathrm{C}=\mathrm{O}$ bond, and the short binding distance and strong binding energy were in tune with the larger charge transfer between FA and Pd/ SWCNT. It was observed that the electrical conductivity of the $\mathrm{Pd} / \mathrm{SWCNT}$ nanotube increased, which directly indicates that the PD/SWCNT is a good sensor for FA detection.

\subsection{Au@ZnO core-shell structure}

Semiconductors have been widely used as FA gas sensors because of their special advantages such as good stability, easy fabrication, and low cost. However, they have a shortcoming in that the operating temperature is too high, sometimes even up to a few hundred degrees centigrade. To solve the problem, researchers synthesized some core-shell structures to reduce the operating temperature, thus enabling real-time monitoring FA in low concentrations. In 2014, Chung et al. ${ }^{77}$ reported an Au@ZnO core-shell structure as a novel sensor to detect shadow level of FA at room temperature. The mechanism for the formation of Au@ZnO is shown in Fig. 26a. The structure's properties have been carefully analyzed with UV-vis spectra, transmission electron microscopy, X-ray diffraction spectra and so on. The possible FA gas sensing mechanism of the sensor is shown in Fig. 26b, which is related to the adsorption of FA, surface reaction with $\mathrm{O}_{2}$, and product desorption in $\mathrm{Au} @ \mathrm{ZnO}$ core-shell nanoparticle. After detection of the Au@ZnO coreshell sensor, the data are immediately collected and analyzed by

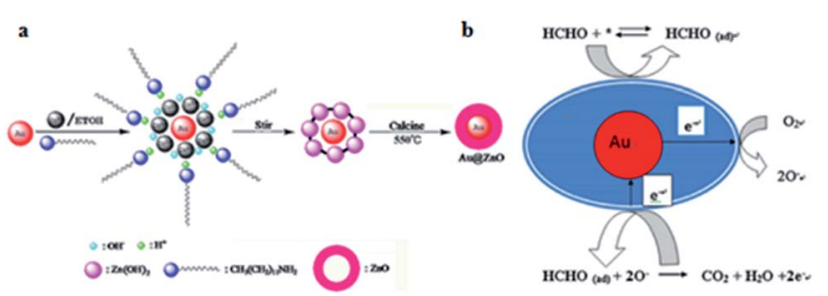

Fig. 26 (a) Schematic of the formation of Au@ZnO; (b) scheme for detection of FA (this figure has been adapted from ref. 77 with permission from Elsevier). 

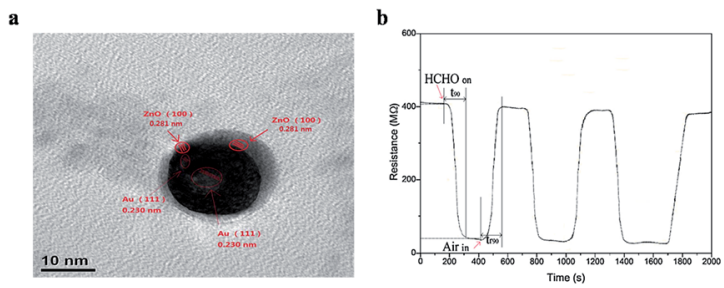

Fig. 27 (a) TEM image of Au@ZnO, (b) resistance signal of the Au@ZnO core shell to $5 \mathrm{ppm}$ formaldehyde gas at room temperature (this figure has been adapted from ref. 77 with permission from Elsevier).

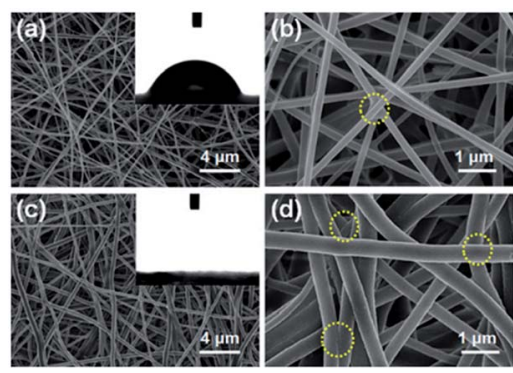

Fig. 28 (a) Low- and (b) high-magnification FE-SEM images of cellulose acetate nanofibers and (c) low- and (d) high-magnification FE-SEM images of cellulose nanofibers. The inset images show the water contact angle (this figure has been adapted from ref. 78 with permission from Elsevier).

a computer connected with the sensing system. Compared with ZnO material, the Au@ZnO core-shell nanoparticles exhibit superior response (138 s) and recovery times (104 s) (Fig. 27).

\subsection{Nanofibrous membranes}

Recently, nanofibrous membranes have been considered to be new simple molecular recognition sites for FA detection. Owing to their superior properties like high porosity and large surface area, nanofibrous membranes have drawn great attention of more and more researchers. For instance, Wang et al. ${ }^{78}$ detected FA using electrospun cellulose nanofibrous membraneimmobilized pararosaniline as a colorimetric sensor. The FESEM images of nanofibers are shown in Fig. 28. Due to their higher specific surface area, nanostructured materials with abundant recognition sites are very appealing. In this research, the color transition mechanism was related to the effects on specific reactions between $\mathrm{FA}$ and pararosaniline. Within a certain range, the color of the system ranged from light pink to purple, and the absorbance intensity was directly proportional to the concentration of FA. The lower limit of detection was approximately $0.06 \mathrm{mg} \mathrm{mL^{-3 }}$ by the naked eye, and the concentration of FA was quantified to be in the $0.12^{-6} \mathrm{mg} \mathrm{m}^{-3}$ range (Fig. 29), indicating sensor's potential application in the detection of trace FA in environmental and biological samples in the future.

Nearly a year later, Dai et al. ${ }^{79}$ described an electrochemical impedimetric sensor based on biomimetic electrospun nanofibers for FA detection. In this research, the recognition

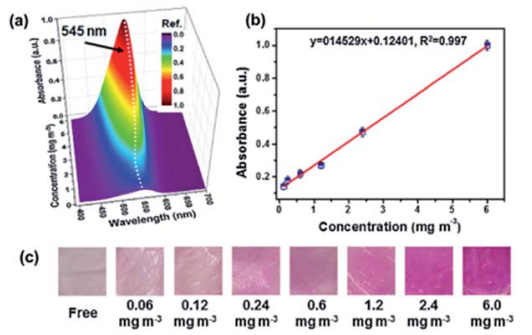

Fig. 29 (a) UV-vis spectra, (b) the absorbance intensity linear curve at $545 \mathrm{~nm}$, and (c) the optical photographs of colorimetric sensors upon exposure to FA at different concentration levels (this figure has been adapted from ref. 77 with permission from Elsevier).

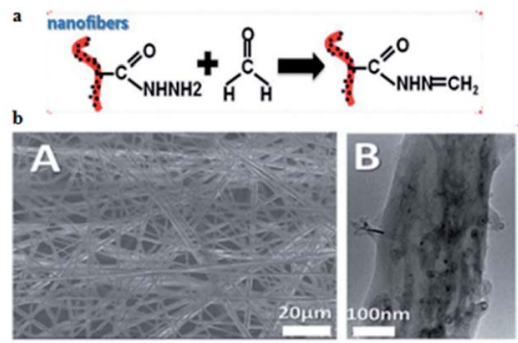

Fig. 30 (a) Schematic of the biomimetic sensing platform for FA. (b) The SEM and TEM images of the electrochemical impedimetric sensor based on biomimetic electrospun nanofibers. The figure has been adapted from the ref. 79 and the artwork can't be modified.
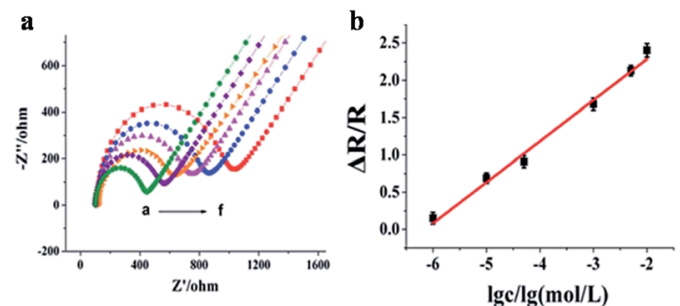

Fig. 31 (a) Impedance spectra of the PMAH/CNTs-NFs/GCE as a function of formaldehyde concentration [(a) $1 \mu \mathrm{mol} \mathrm{L}{ }^{-1}$, (b) $10 \mu \mathrm{mol}$ $\mathrm{L}^{-1}$, (c) $50 \mu \mathrm{mol} \mathrm{L}-1$, (d) $3 \mathrm{mmol} \mathrm{L}^{-1}$, (e) $5 \mathrm{mmol} \mathrm{L}^{-1}$, (f) $10 \mathrm{mmol} \mathrm{L}^{-1}$ ] in $0.1 \mathrm{~mol} \mathrm{~L}^{-1} \mathrm{KCl}$ containing $5 \mathrm{mmol} \mathrm{L}^{-1}\left[\mathrm{Fe}(\mathrm{CN})_{6}\right]^{3 / 4}$. (b) Calibration curve for the electrospun sensor (this figure has been adapted from ref. 79 with permission from RSC).

mechanism was related to obvious changes by reactions between recognition sites on nanofibers and FA (Fig. 30a) and the mechanism could be monitored through electrochemical impedance spectroscopy. The SEM and TEM images of the nanofiber are shown in Fig. 30b. The concentration of FA was quantified to be in the $1-1000 \mu \mathrm{mol} \mathrm{L}^{-1}$ range using the described method, and the limit of detection was $0.8 \mu \mathrm{mol} \mathrm{L} \mathrm{L}^{-1}$. Herein, it was also observed that the electrospun nanofibers for FA detection were designed as a bio-recognition element for the first time; hence, it is believed that the biomimetic impedimetric sensor based on nanofibers can prepare further new artificial biosensors to monitor FA in environmental, food and biological samples (Fig. 31). 
Moreover, there are some other nanomaterials such as nano thin films and nanosheets that have been reported as great sensors for detection of FA in the environment, ${ }^{\mathbf{8 0}, 81}$ Sira Srinivesa et al. synthesized a polyaniline (PANI) nanothin film as a chemiresistor sensor to trace FA, and the sensing mechanism was that a Schiff base derived from the reaction between the amines and FA changed the resistance of the PANI film. ${ }^{\mathbf{8 0}} \mathrm{Yu}$ et al. designed high-performance sensor strips using ultrathin $\mathrm{SnO}_{2}$ nanosheets. ${ }^{\mathbf{8 1}}$ In summary, owing to nanomaterials' special characterizations for affording large surface areas and more direct conduction pathways, they play an important role in FA detection.

\section{Conclusion and prospective}

To date, many types of FA detection methods have been reported, including biosensor methods, ${ }^{82}$ Raman spectroscopy, ${ }^{83}$ gas chromatography, ${ }^{84}$ liquid chromatography ${ }^{85}$ and, colorimetric detection method. ${ }^{86}$ Each detection method has different characteristics; spectrophotometry has some advantages such as low cost, simple equipment and fast operation, but gives low accuracy and is often influenced by complex samples. Chromatography has been widely used for detecting FA in the scientific field because of its high sensitivity, convenient and rapid operation and high recovery rate. However, it requires complex equipment and a long time for purification, hindering it from satisfying the market demand.

Optical imaging is a powerful noninvasive alternative because it can be applied in living systems with minimal perturbation. Small-molecule probes that make use of biorthogonal chemical transformations have been employed to detect a variety of bioanalytes via signal molecules. In comparison to semiconductor sensors based on gas-sensitive films, fluorescent sensors have an obvious advantage in terms of sensitivity. Some new approaches are reported for the detection of FA in living cells through the development of fluorescent probes in the last two years, which enable real-time, in situ detection of FA in a compact and reusable manner. These probes available across a wide spectrum of light and exhibiting a variety of cellular and subcellular capabilities are now being used in developing technologies that realise further exploration of biological systems. In particular, key points should be focused on to develop more sensitive and unique probes that can detect endogenous levels of FA. More accurate quantitative measurements applied by FA probes are also a priority, allowing for wide application in biomedical research.

Meanwhile, nanomaterial-based probes for detection of FA have been vastly improved through different methods such as SRES, RRS, and DDT in the past few years. Various nanomaterials such as nanoparticles, nanotubes, nanosheets, and core-shell structures have been developed owing to their ability to significantly improve FA sensing and expand the application fields. In conclusion, because of the special optical and electrical properties mentioned above, nanomaterials, the best SERS substrates, have become suitable candidates to trace FA with good reactivity, high selectivity, and lower limit of detection in environmental, food and biological samples.
Although there have been many studies for the detection of endogenous FA in recent years, some basic and key issues need to be addressed through further research and breakthrough. For example, there are still no trappable or targetable probes offering the ability of monitoring FA in individual cells in order to better understand intracellular movement of these species, especially between different cell and tissue types. Furthermore, the interactions of FA with other reactive species like nitric oxide, hydrogen peroxide, carbon monoxide, and higher order reactive nitrogen, oxygen, and carbon species has not been investigated. To the best of our knowledge, there is no report about an approach that can detect them in clinical trials. The recent studies are fragmented, and more studies focusing on FA sensing in clinical trials need to be conducted, considering the influence of pathological condition and individual differences; additionally, visualizing deeper tissues on currently reported optical imaging probes for FA detection is difficult to. Moreover, the unsatisfactory biocompatibility of imaging agents makes it difficult for them to accommodate the biological environment and have a wide range of applications. To tackle this problem, there are several proposed approaches. New sensor technologies that possess the features of facile operation, high sensitivity, and real-time and online detection are needed to enable real-time, in situ detection of FA in a compact and reusable manner. Of note, new strategies such as PET, MRI, and fMRI will be influential in the development of novel FA imaging agents, leading to better detection in physiological and even in pathological conditions.

\section{Acknowledgements}

This research was supported in part by National Natural Science Foundation of China (81671756 and 81671676), Doctoral Fund of Ministry of Education of China (No. 20120162110070).

\section{Notes and references}

1 R. G. Liteplo and M. E. Meek, J. Toxicol. Environ. Health, Part $B, 2003,6,85-114$.

2 O. Merk and G. Speit, Environ. Mol. Mutagen., 1998, 32, 260268.

3 X. Q. Zhao and Z. Q. Zhang, Talanta, 2009, 80, 242-245.

4 F. X. Li, J. Lu, Y. J. Xu, Z. Q. Tong, C. L. Nie and R. Q. He, Prog. Biochem. Biophys., 2008, 35, 393-400.

5 X. J. Tang, Y. Bai, A. Duong, M. T. Smith, L. Li and L. Zhang, Environ. Int., 2009, 35, 1210-1224.

6 T. Noda, A. Takahashi, N. Kondo, E. Mori, N. Okamoto, Y. Nakagawa, K. Ohnishi, M. Z. Zdzienicka, L. H. Thompson, T. Helleday, H. Asada and T. Ohnishi, Biochem. Biophys. Res. Commun., 2011, 404, 206-210.

7 R. L. Bunde, E. J. Jarvi and J. J. Rosebtreter, Talanta, 2000, 51, 159-171.

8 R. Kataky, M. R. Bryce, L. Goldenberg, S. Hayes and A. Novak, Talanta, 2002, 56, 451-458.

9 N. Wang, X. Wang, Y. Ji, X. Li, J. Yu and B. Ding, Carbohydr. Polym., 2014, 108, 192-199. 
10 Y. H. Zhu, H. Li, Q. Zheng, J. Q. Xu and X. X. Li, Langmuir, 2012, 28, 7843-7850.

11 Z. Zhang, C. Zhao, Y. Ma and G. Li, Analyst, 2014, 139, 36143621.

12 Z. Y. Gu, G. Wang and X. P. Yan, Anal. Chem., 2010, 82, 13651370.

13 S. Antwi-Boampong and J. J. BelBruno, Sens. Actuators, B, 2013, 182, 300-306.

14 J. F. Liu, J. F. Peng, Y. G. Chi and G. B. Jiang, Talanta, 2005, 65, 705-709.

15 A. Allouch, M. Guglielmino, P. Bernhardt, C. A. Serra and S. Le Calve, Sens. Actuators, B, 2013, 181, 551-558.

16 F. C. Chung, R. J. Wu and F. C. Cheng, Sens. Actuators, B, 2014, 190, 1-7.

17 K. Mitsubayashi, G. Nishio, M. Sawai, T. Saito, H. Kudo, H. Saito, K. Otsuka, T. Noguer and I. L. Marty, Sens. Actuators, B, 2008, 130, 32-37.

18 O. Demkiv, O. Smutok, S. Paryzhak, G. Gayda, Y. Sultanov, D. Guschin, H. Shkil, W. Schuhmann and M. Gonchar, Talanta, 2008, 76, 837-846.

19 M. J. Dennison, J. M. Hall and A. P. F. Turner, Analyst, 1996, 121, 1769-1773.

20 E. X. Chen, H. Yang and J. Zhang, Inorg. Chem., 2014, 53, 5411-5413.

21 J. B. Zeng, S. G. Fan, C. Y. Zhao, Q. R. Wang, T. Y. Zhou, X. Chen, Z. F. Yan, Y. P. Li, W. Xing and X. D. Wang, Chem. Commun., 2014, 50, 8121-8123.

22 X. Chen, T. Pradhan, F. Wang, J. S. Kim and J. Yoon, Chem. Rev., 2012, 112, 1910-1956.

23 C. Y. Lee, C. M. Chiang, Y. H. Wang and R. H. Ma, Sens. Actuators, B, 2007, 122, 503-510.

24 C. H. Chou, J. L. Chang and J. M. Zen, Sens. Actuators, B, 2010, 147, 669-675.

25 J. Wang, L. Liu, S. Y. Cong, J. Q. Qi and B. K. Xu, Sens. Actuators, B, 2008, 134, 1010-1015.

26 P. Lv, Z. A. Tang, J. Yu, F. T. Zhang, G. F. Wei, Z. X. Huang and Y. Hu, Sens. Actuators, B, 2008, 132, 74-80.

27 D. A. Mankoff, J. Nucl. Med., 2007, 48, 18-21.

28 J. M. Hoffman and S. S. Gambhir, Radiology, 2007, 244, 3947.

29 J. Wang, P. Zhang, J. Q. Qi and P. J. Yao, Sens. Actuators, B, 2009, 399-404.

30 T. F. Massoud and S. S. Gambhir, Trends Mol. Med., 2007, 13, 183-191.

31 R. Weissleder and M. J. Pittet, Nature, 2008, 452, 580-589.

32 M. A. Pysz, S. S. Gambhir and J. K. Willmann, Clin. Radiol., 2010, 65, 500-516.

33 C. H. Contag, Annu. Rev. Phytopathol., 2007, 2, 277-305.

34 J. K. Willmann, N. V. Bruggen, L. M. Dinkelborg and S. S. Gambhir, Nat. Rev. Drug Discovery, 2008, 7, 591-607.

35 H. R. Herschman, Science, 2003, 302, 605-608.

36 T. Lammers, F. Kiessling, W. E. Hennink and G. Storm, Mol. Pharm., 2010, 7, 1899-1912.

37 V. Ntziachristos, J. S. Yoo and G. M. van Dam, J. Biomed. Opt., 2010, 15, 759-765.

38 Y. Urano, M. Sakabe, N. Kosaka, M. Ogawa, M. Mitsunaga, D. Asanuma, M. Kamiya, M. R. Young, T. Nagano,
P. L. Choyke and H. Kobayashi, Sci. Transl. Med., 2011, 3, 110-119.

39 J. V. Frangioni, J. Clin. Oncol., 2008, 26, 4012-4021.

40 V. K. Gupta, S. Agarwal, A. Jakob and H. Lang, Sens. Actuators, B, 2006, 114, 812-818.

41 A. K. Jain, A. K. Gupt, P. A. Ganeshpure and J. R. Raisoni, Anal. Chim. Acta, 2005, 553, 177-184.

42 T. Liu, Y. F. Zhang, T. T. Hou, Q. W. Xue, L. Wang and S. H. Wang, RSC Adv., 2017, 7, 23422-23426.

43 R. K. Mahajan, I. Kaur and M. Kumar, Sens. Actuators, B, 2003, 91, 26-31.

44 M. N. Descamps, T. Bordy, J. Hue, S. Mariano, G. Nonglaton, E. Schultz, T. H. Tran-Thi and S. Vignoud-Despond, Procedia Eng., 2010, 5, 1009-1012.

45 T. Liu, G. He, M. Yang and Y. J. Fang, J. Photochem. Photobiol., A, 2009, 202, 178-184.

46 S. L. Wang, X. B. Wang, X. X. Chen, X. Z. Cao, J. Cao, X. F. Xiong and W. B. Zeng, RSC Adv., 2016, 6, 46317-46324.

47 Z. J. Huang, F. W. Yan and G. Q. Yuan, RSC Adv., 2017, 7, 1318-1325.

48 H. S. Song, S. Rajendiran, N. S. Kim, S. K. Jeong, E. H. Koo, G. S. Park, T. D. Thangaduraia and S. H. Yoon, Tetrahedron Lett., 2012, 53, 4913-4916.

49 D. P. Kennedy, C. M. Kormos and S. C. Burdette, J. Am. Chem. Soc., 2009, 131, 8578-8586.

50 W. Zhou, H. Dong, H. Yan, C. X. Shi, L. H. Wei and Z. X. Li, Sens. Actuators, B, 2015, 209, 664-669.

51 C. X. Liu, C. X. Shi, H. X. Li, W. W. Du, Z. X. Li, L. H. Wei and M. M. Yu, Sens. Actuators, B, 2015, 219, 185-191.

52 B. L. Dong, X. Z. Song, Y. H. Tang and W. Y. Lin, Sens. Actuators, B, 2016, 222, 325-330.

53 Y. H. Tang, X. Q. Kong, A. Xu, B. L. Dong and W. Y. Lin, Angew. Chem., Int. Ed., 2016, 55, 3356-3359.

54 H. Yu, Y. Xiao and L. Jin, J. Am. Chem. Soc., 2012, 134, 1748617489.

55 Y. H. Lee, Y. H. Tang, P. Verwilst, W. Y. Lin and J. S. Kim, Chem. Commun., 2016, 52, 11247-11250.

56 J. Chen, L. Zeng, T. Xia, S. Li, T. Yan, S. Wu, G. Qiu and Z. Liu, Anal. Chem., 2015, 87, 8052-8056.

57 Z. Li, Z. Xue, Z. Wu, J. Han and S. Han, Org. Biomol. Chem., 2011, 9, 7652-7654.

58 T. Wang, E. F. Douglass, K. J. Fitzgerald and D. A. Spiegel, J. Am. Chem. Soc., 2013, 135, 12429-12433.

59 M. Togashi, T. Terai, H. Kojima, K. Hanaoka, K. Igarashi, Y. Hirata, Y. Urano and T. Nagano, Chem. Commun., 2014, 50, 14946-14948.

60 A. Roth, H. Li, C. Anorma and J. Chan, J. Am. Chem. Soc., 2015, 137, 10890-10893.

61 T. F. Brewer and C. J. Chang, J. Am. Chem. Soc., 2015, 137, 10886-10889.

62 L. W. He, X. L. Yang, Y. Liu, X. Q. Kong and W. Y. Lin, Chem. Commun., 2016, 52, 4029-4032.

63 R. Roy, S. Komarneni and D. M. Roy, Materials Research Society Proceedings, 1984, 32, 347-351.

64 S. H. Hsu, M. C. Wu, S. Chen, C. M. Chuang, S. H. Lin and W. F. Su, Carbon, 2012, 50, 896-905. 
65 M. Aeschlimann, M. Bauer, D. Bayer and T. Brixner, Nature, 2007, 446, 301-304.

66 J. F. Li, X. D. Tian, S. B. Li, J. R. Anema, Z. L. Yang, Y. Ding, Y. F. Wu, Y. M. Zeng, Q. Z. Chen, B. Ren, Z. L. Wang and Z. Q. Tian, Nat. Protoc., 2012, 8, 52-65.

67 K. Vangala, M. Yanney, C. T. Hsiao, W. W. Wu, R. F. Shen, S. Zou, A. Sygula and D. Zhang, Anal. Chem., 2010, 82, 10164-10171.

68 X. X. Han, P. Pienpinijtham, B. Zhao and Y. Ozaki, Anal. Chem., 2011, 83, 8582-8588.

69 W. Gang and L. Qu, Nanoscale, 2012, 7358-7361.

70 P. Ma, F. H. Liang and D. Wang, Microchim. Acta, 2015, 182, 863-869.

71 Z. M. Zhang, C. Zhao and Y. Ma, Analyst, 2014, 3614-3621.

72 J. Zhang, P. P. Guan, W. Li and Z. Q. S. H. Zhai, Instrum. Sci. Technol., 2016, 44, 249-258.

73 X. Chi, C. B. Liu, L. Liu, S. Li, H. Li and X. Zhang, Mater. Sci. Semicond. Process., 2014, 18, 160-164.

74 F. Fang, L. Bai and D. S. Song, Sensors, 2015, 15, 2008620096.

75 G. Q. Wen, X. J. Liang, A. H. Liang and Z. Jiang, Plasmonics, 2015, 10, 1081-1088.
76 M. Yoosefiana, H. Raissi and A. Mola, Sens. Actuators, B, 2015, 212, 55-62.

77 F. C. Chung, Z. Zhu, P. Y. Luo, R. J. Wu and W. Li, Sens. Actuators, B, 2014, 199, 314-319.

78 X. Q. Wang, Y. Li, X. Q. Li, J. Yu, S. S. Al-Deyab and B. Ding, Sens. Actuators, B, 2014, 203, 333-339.

79 H. Dai, L. S. Gong, G. F. Xu, X. Li, S. Zhang and Y. Lin, Analyst, 2014, 140, 582-589.

80 S. Srinivesa, T. Sarkara and A. Mulchandani, Sens. Actuators, $B, 2014,194,255-259$.

81 H. Yu, T. Y. Yang and R. Zhao, RSC Adv., 2015, 104, 574-581.

82 M. Rey-Mansilla, C. Gonzalez Sotelo and R. I. Perez-Martin, Food Sci., 2002, 67, 3242-3251.

83 F. Bianchi, M. Careri, M. Musci and A. Mangia, Food Chem., 2007, 100, 1049-1053.

84 W. J. Duan, D. Q. Zhou and R. L. Zhang, Chinese Agric. Sci. Bull., 2011, 27, 383-390.

85 X. Y. Fu, C. H. Xue, B. C. Miao, Z. J. Li, Y. Q. Zhang and Q. Wang, Food Chem., 2007, 103, 287-294.

86 L. Feng, C. J. Musto and K. S. Suslick, J. Am. Chem. Soc., 2010, 132, 4046-4047. 